\title{
Assessment of Nutritional and Inflammatory Status to Determine the Prevalence of Malnutrition in Patients Undergoing Surgery for Colorectal Carcinoma
}

\author{
ANTONELLA DANIELE, ROSA DIVELLA, INES ABBATE, \\ ADDOLORATA CASAMASSIMA, VITO MICHELE GARRISI, EUFEMIA SAVINO, \\ PORZIA CASAMASSIMA, EUSTACHIO RUGGIERI and RAFFAELE DE LUCA \\ National Cancer Research Centre, Istituto Tumori “Giovanni Paolo II”, Bari, Italy
}

\begin{abstract}
Background/Aim: Colorectal Cancer is the fourth most frequent cause of cancer death worldwide and its incidence increases from 50 years of age. It is often associated with protein-caloric malnutrition and $20 \%$ of cancer deaths occur due to this event. The aim of this study was to assess the prevalence of malnutrition and inflammatory status in 78 patients undergoing surgery for colorectal carcinoma. Patients and Methods: Nutritional Status was assessed by Mini Nutritional Assessment (MNA). Serum levels of interleukin-6 (IL-6) and tumor necrosis factor- $\alpha(T N F-\alpha)$ were measured by ELISA, while albumin, $C$-reactive protein $(C R P)$ and transferrin $(T R F)$ were tested using an immunometric assay. Results: The mean MNA score in colorectal patients was 20.4 \pm 8.4 , while $23 / 78$ patients $(29.4 \%)$ were well nourished, $36 / 78$ (46.1\%) were at risk of malnutrition and 19/78 (24.3\%) were malnourished, reporting in the previous six months from the date of diagnosis a significant weight loss $(>10$ $\mathrm{kg}$ ), muscle mass loss and severe reduction of food intake due to loss of appetite and altered taste perception. The serum means of IL-6, TNF- $\alpha$ and CRP, were significantly higher in colorectal patients compared to the control group ( $p<0.001, p<0.0001, p<0.0001$, respectively) while lower TRF, albumin and HCT serum levels in cancer patients vs. healthy subjects $(p<0.0001 ; p<0.0001$ and $p<0.0001)$ were found. Conclusion: more than 50\% of colorectal cancer patients were malnourished or at risk of malnutrition and reported an imbalance between nutritional and inflammatory status. They, therefore,
\end{abstract}

Correspondence to: Antonella Daniele, Biologist, National Cancer Centre, Istituto Tumori "Giovanni Paolo II", Viale Orazio Flacco 65, 70124 Bari, Italy. Tel/Fax: +39 805555259, e-mail: antonella27@inwind.it

Key Words: Mini nutritional assessment, malnutrition, cytokines, inflammatory markers, colorectal cancer. require a nutritional intervention before treatment in order to have a more effective response and improve quality of life.

Colorectal cancer (CRC) is the fourth most frequent cause of cancer-related death worldwide and its incidence increases from 50 years of age. There is no significant difference between the genders regarding the colic location, while for rectal localization frequency is higher in men $(1,2)$. Worldwide, the incidence rate of this cancer is the fourth highest in men (after lung, prostate and stomach cancer) and the third in women (after breast and cervical cancer). As for mortality, CRC is in fourth place for men (after lung, stomach and liver) and fifth for women (after breast, lung, cervix and stomach). They are 678,000 new cases a year worldwide, with 150,000 in Europe. The incidence in Italy in 2015 was 257,100 new cases $(29,100$ men and 22,800 women) and the highest rates are recorded in central and northern Italy (3).

The term "colorectal" cancer includes cancers of the colon, the sigmoid rect-junction and rectum that arise from similar tissues. The site most frequently affected by the pathology is the proximal colon $(38.8 \%)$, followed by the distal colon (29.6\%) and the rectum (28.5\%), while the remaining tumors (about 1\%) have multiple sites (4). The histological type most frequently found is adenocarcinoma, which accounts for $90-95 \%$ of all colorectal cancers (5).

CRC is the result of a complex interaction of genetic and environmental factors; It most commonly occurs as a sporadic form and only $5 \%$ as a hereditary form (6). Genetic susceptibility to colon cancer has been attributed both to polyposis and non-polyposis syndromes $(7,8)$. Among nongenetic risk factors for the development of CRC, the most important are a sedentary lifestyle and obesity. In fact, proper diet (a low fat intake and consumption of red meat and a high intake of vegetable fibers), along with frequent physical activity seem to be the best prevention tools for this malignant disease (9-11). 
Non-dietary risk factors for the onset of colorectal cancer seem to be tobacco smoke (12), alcohol (more than $30 \mathrm{~g} /$ day) (13) and the presence of inflammatory bowel diseases such as ulcerative colitis or Crohn's disease (14).

Most early stage disease is detected following colonoscopy screening, but patients found to have a colorectal cancer after symptoms onset tend to have an advanced disease. Tumor resection is the only curative modality for localized disease while adjuvant chemotherapy regimens have demonstrated a role in increasing cure rates and reducing changes of recurrence among patients with stage III disease (15).

In patients who undergo surgical resection for colorectal adenocarcinoma, an energy deficit-protein often arises known as protein-energy malnutrition (PEM). This condition is characterized by an alteration of the function, structure and development of the organism resulting in an imbalance between energy needs, revenues and utilization of nutrients, leading to excess morbidity and mortality and impaired quality of life.

Energy-protein malnutrition has a negative impact on the quality and duration of the life of cancer patients; it is estimated that in $48-61 \%$ of colorectal tumors there is a weight loss of at least $10 \%$. (16). A correlation between the extent of weight loss and survival of CRC patients, as well as between increased energy consumption and weight loss, has been demonstrated. (17). In fact, the increase in the Basal Metabolic Rate (BMR) of cancer patients, is evaluated to be between 14 and $41 \%$ compared to a healthy subject, equivalent to a monthly loss of $1.2 \mathrm{~kg}$ of muscle mass and $0.5-1 \mathrm{~kg}$ of body fat. It is, therefore, necessary, for accurate nutritional assessment of the patient undergoing surgical resection for colorectal cancer to be carried out, in order to avoid the risk of developing a state of malnutrition with consequent recourse to artificial nutrition thus preventing cancer cachexia and to strengthen the response to chemo or radio treatments. In fact, in these patients a nutritional assessment is required taking into account both the metabolic changes due to tumor growth and protein depletion resulting from surgery.

The nutritional status assessment can be approached by simultaneous use of clinical, anthropometric and biochemical markers that are necessary to make a comprehensive diagnosis. Cytokines are important modulators of immune response, and IL- 6 and TNF- $\alpha$ are associated with several disorders such as inflammation, or autoimmune or malignant disease. IL-6 is a $26-\mathrm{kDa}$ polypeptide released from adipocytes (18); increased IL- 6 and TNF- $\alpha$ levels leads to a low appetite and reduce food intake in order to regulate body weight (19), and stimulate lipolysis in the muscles increasing fat oxidation and esterification of fatty acid (20). As widely reported in the literature, the blood chemistry parameters that represent the state of malnutrition related to both neoplastic and non-neoplastic diseases are albumin, transferrin (TRF), and the hematocrit value, which are found in lower concentrations in malnourished patients based on the normal range, and C-reactive protein (CRP) which tends to be higher in line with the concentrations of IL-6 and TNF- $\alpha$ (21-25).

A first step is to make a multi-parameter assessment of nutritional status and score that helps determine the degree of malnutrition and identify patients at high or medium risk of malnutrition; as a second step it is necessary to consider the most appropriate nutritional strategies to meet the energy demands of the patient with CRC. The aim of this study was to assess the prevalence of malnutrition and inflammatory status in patients undergoing surgery for colorectal carcinoma in order to offer timely nutritional support and thus avert the risk of cancer cachexia and ineffectiveness of post-surgical treatment with chemo or radio-therapy.

\section{Patients and Methods}

The study had a cross-sectional design and was approved by the ethics committee of the National Cancer Research Centre (NCRC), Istituto Tumori "Giovanni Paolo II" of Bari. Between November 2014 and September 2015, seventy-eight patients (39 women and 39 men) undergoing resection surgery for colorectal cancer and 30 healthy subjects were enrolled in this study. The control group was constituted by healthy volunteers recruited within our institution. Those willing to participate signed informed consent, and serum sample was drawn into Eppendorf tubes and immediately frozen at $-20^{\circ} \mathrm{C}$ until analysis. For each patient and healthy volunteer an assessment of nutritional status was carried out using Mini Nutritional Assessment (MNA).

Pathology. Histological type was assessed by the World Health Organization (WHO) system, tumor staging was evaluated according to the TNM-UICC system (26), and nuclear cytohistological tumor grade was determined according to the Elston-Ellis criteria. Information about age, histological diagnosis, type of surgery, histological type (adenocarcinoma NAS or other type), clinical pathology such as tumor size (T), lymph node status $(\mathrm{N})$, the presence of metastases $(\mathrm{M})$ was collected for each patient through clinical charts.

Mini nutritional assessment. All the included CRC patients were anthropometrically evaluated using common methods such as weight, height, waist, calf and mid-upper-arm circumference and Body Mass Index (BMI) calculated as weight divided by height squared $\left(\mathrm{kg} / \mathrm{m}^{2}\right)$ (27). Nutritional status was defined according to the Mini Nutritional Assessment (MNA) scale (28). The MNA is a rapid method of nutrition assessment validated in three studies on more than 600 subjects by the Centre of Internal Medicine and Clinical Gerontology of Toulouse (France), the Clinical Program at the University of new Mexico (USA) and the Nestlé Research Centre In Lausanne (Switzerland) and comprises 18 items grouped in four sections: anthropometric assessment (weight, height, weight and appetite loss; general assessment (mobility, lifestyle, number of drugs pro/die, presence of emotional stress or depression), dietary assessment (number of daily full meals, variety of food and fluid intake and autonomy of feeding), and subjective assessment (selfperception of health, physical appearance and nutritional status). 
Each answer has a numeric value (between 0 and 3 ) that contributes to the final score for a total of 30 ; a score from 24 to 30 indicates a normal nutritional status; from 17 to 23.5 indicates a risk of malnutrition and a score less than 17 indicate a protein energy malnutrition (29-34).

The assessment of fatty free mass (FFM) and fat mass (FM) was carried out according to Durnin-Womersley scheme (Progeo s.r.1. 2012-2015-Italy), measuring 4 folds: biceps, triceps, subscapularis, and suprailliac by plicometer FAT-1 (GIMA s.r.l.- Italy). The normal range for FFM percentage was 8-25\% for men and 8-34\% for women.

Laboratory parameters detection. Inflammatory parameters such as IL-6 and TNF- $\alpha$ were measured with enzyme-linked immunosorbent assay (ELISA) according to the manufacturer's instructions (Human IL-6 Quantikine ELISA Kit and Human TNFalpha Quantikine ELISA Kit- R\&D Systems, Italy).

Briefly, standards and samples were added into each well of the microplate on the bottom of which were bound specific monoclonal antibodies; any amount of IL- 6 and TNF- $\alpha$ present was bound by the immobilized antibody. After washing away any unbound substances, an enzyme-linked polyclonal antibody against IL-6 or TNF- $\alpha$ conjugated to horseradish peroxidase was added to the wells . Following a wash, a substrate solution was added to the wells and color developed in proportion to the amount of IL- 6 and TNF- $\alpha$ bound in the initial step. The color development was stopped and the intensity of the color was read at $540 \mathrm{~nm}$ for IL- 6 and to 650 $\mathrm{nm}$ for TNF- $\alpha$ in a microtiter plate spectrophotometer (Multiskan Ascent-Lab Systems, Milan, Italy). Values of IL- 6 between 3.13 and $12.5 \mathrm{pg} / \mathrm{ml}$. were considered normal, and TNF- $\alpha$ values between 0.5 and $5.5 \mathrm{pg} / \mathrm{ml}$ were considered normal. The determinations were made in duplicate; the sensitivity of the ELISA tests for IL-6 and TNF- $\alpha$ were $<0.70 \mathrm{pg} / \mathrm{ml}$ and $0,191 \mathrm{pg} / \mathrm{ml}$ respectively.

Serum albumin, C-Reactive Protein (CRP), and Transferrin were measured by COBAS c311/501 (Roche-Diagnostic Limited S.p.ABasel-Switzerland); the Hematocrit (HCT) level was measured by the "Coulter Cellular Analysis System" (Unicell DX H800, Beckman-Coulter S.r.l.-Milano, Italy). The normal range of each analyte is reported in Table I.

Statistical analysis. All statistical analyses were performed using NCSS-PASS (statistical analysis and size power analysis and graphics) 2007 software. The serum levels of laboratory parameters are expressed as means \pm standard deviation. The correlation between IL-6, TNF- $\alpha$, CRP, transferrin albumin and HCT serum levels in CRC patients $v s$. the control group were performed by the $t$-test; the correlations between serum levels of laboratory parameters and anthropometric measurements into 3 sub-groups of CRC patients (malnourished, well-nourished and at risk of malnutrition) were performed with analysis of variance (ANOVA). A $p$-value of less than 0.05 was considered as statistically significant. For correlation of anthropometric measurements with and between laboratory parameter levels, we used Pearson's r-test; a $0.3<\mathrm{r}<0,7$ value was considered a good positive association.

\section{Results}

Baseline characteristics for Colorectal Cancer patients are shown in Table I. Between November 2014 and September 2015, seventy-eight patients (39 women and 39 men) aged from 44 to 87 years (median: 78 yrs) undergoing resection
Table I. Baseline clinical characteristic of 78 CRC patients.

\begin{tabular}{|c|c|c|}
\hline Charateristics & $\mathrm{n}^{\circ}$ & $\%$ \\
\hline \multicolumn{3}{|l|}{ Gender } \\
\hline Male & 39 & 50.0 \\
\hline Female & 39 & 50.0 \\
\hline \multicolumn{3}{|l|}{ Tumor Site } \\
\hline Colon & 25 & 32 \\
\hline Sigma & 13 & 17 \\
\hline Rectum & 40 & 51 \\
\hline \multicolumn{3}{|l|}{ Histological type } \\
\hline Adenocarcinoma & 75 & 96 \\
\hline Mucinous Carcinoma & 1 & 3 \\
\hline Tubular Carcinoma & 2 & 1 \\
\hline \multicolumn{3}{|l|}{ Stadio } \\
\hline I & 2 & \\
\hline II & 4 & \\
\hline III & 15 & \\
\hline IV & 47 & \\
\hline \multicolumn{3}{|l|}{ Grade } \\
\hline G1 & 4 & \\
\hline G2 & 36 & \\
\hline G3 & 38 & \\
\hline Blood chemistry parameters & Range & Median value \\
\hline Albumin & $(3.4-5.7) \mathrm{g} / \mathrm{dL}$ & $2.77 \mathrm{~g} / \mathrm{dL}$ \\
\hline Transferrin & $(260-460) \mathrm{mg} / \mathrm{dL}$ & $118,7 \mathrm{mg} / \mathrm{dL}$ \\
\hline CRP & $(0.0-0.5) \mathrm{mg} / \mathrm{dL}$ & $4.0 \mathrm{U} / \mathrm{L}$ \\
\hline Hematocrit value & $(40-52) \%$ & $37.3 \mathrm{U} / \mathrm{L}$ \\
\hline IL-6 & $(3.13-12.5) \mathrm{pg} / \mathrm{ml}$ & $10.8 \mathrm{pg} / \mathrm{dL}$ \\
\hline TNF- $\alpha$ & $(0.5-5.5) \mathrm{pg} / \mathrm{ml}$ & $5.2 \mathrm{pg} / \mathrm{ml}$ \\
\hline
\end{tabular}

CRP: C-reactive protein; IL-6: interleukin-6; TNF- $\alpha$ : tumor necrosis factor- $\alpha$.

surgery for colorectal cancer were enrolled in this study together with 30 healthy subjects. The control group was constituted by healthy volunteers, aged from 40 to 70 years (median: 50 years) recruited within our institution. A statically significant correlation between serum levels of IL6 , TNF- $\alpha$, CRP, TRF, albumin and hematocrit level in CRC patients $v s$. the control group was found. The mean serum IL-6 and TNF- $\alpha$ levels of the 78 CRC patients were $14.5 \pm 12.8 \mathrm{pg} / \mathrm{ml}$ and $10.1 \pm 12.5 \mathrm{pg} / \mathrm{ml}$ respectively, significantly higher than those of the 30 subjects in the 30 control group, $6.5 \pm 2.5 \mathrm{pg} / \mathrm{ml}$ for IL-6 ( $p=0.001, t$-test), and $3.2 \pm 2.8 \mathrm{pg} / \mathrm{ml}$ for TNF- $\alpha(p<0.0001, t$-test $)$.

The mean CRP levels in CRC patients were higher than in the control group $(5.3 \pm 5,4 \mathrm{mg} / \mathrm{dl} v s .0 .2 \pm 2.5 \mathrm{mg} / \mathrm{dl}$; $p<0.0001, t$-test) while lower mean TRF levels were observed in CRC patients vs. healthy subjects $(184.2 \pm 68.7$ $\mathrm{mg} / \mathrm{dl} v s .350 \pm 57 \mathrm{mg} / \mathrm{dl} ; p<0.0001, t$-test). Furthermore, a significant correlation between albumin serum levels and hematocrit value in CRC patients and the control group was observed; the means of albumin and HCT serum levels in 
Table II. Comparison between mean \pm standard deviation of nutritional and inflammatory parameters in three subgroup CRC patients.

\begin{tabular}{|c|c|c|c|c|}
\hline & Well nourished & At risk malnutrition & Malnourished & p-Value \\
\hline Age (yrs) & $68.9 \pm 11.3$ & $65.8 \pm 8.4$ & $69.1 \pm 3.5$ & \\
\hline \multicolumn{5}{|l|}{ Gender } \\
\hline Male $(\%)$ & 57 & 42 & 58 & \\
\hline Female $(\%)$ & 43 & 58 & 42 & \\
\hline MNA score & $25.7 \pm 2.4$ & $20.5 \pm 1.0$ & $13.6 \pm 2.8$ & \\
\hline $\operatorname{BMI}\left(\mathrm{Kg} / \mathrm{m}^{2}\right)$ & $27.7 \pm 1.8$ & $24.7 \pm 3.17$ & $24 \pm 4.9$ & $<0.0001$ \\
\hline Waist Circumference $(\mathrm{cm})$ & $97.5 \pm 5.6$ & $92.3 \pm 12.7$ & $87.2 \pm 14.1$ & 0.019 \\
\hline Hematocrit $(\%)$ & $40.4 \pm 9.6$ & $37.1 \pm 1.2$ & $34.7 \pm 2.2$ & 0.004 \\
\hline Albumin (g/dl) & $3.4 \pm 0.31$ & $2.7 \pm 0.29$ & $2.5 \pm 0.74$ & $<0.0001$ \\
\hline Transferrin (mg/dl) & $233.6 \pm 33.2$ & $189.3 \pm 2.12$ & $162.9 \pm 4.9$ & $<0.0001$ \\
\hline $\mathrm{CRP}(\mathrm{mg} / \mathrm{dl})$ & $3.9 \pm 1.08$ & $4.8 \pm 0.88$ & $7.8 \pm 1.25$ & $<0.0001$ \\
\hline IL-6 (pg/ml) & $7.14 \pm 2.3$ & $13.5 \pm 1.8$ & $25.1 \pm 2.5$ & $<0.0001$ \\
\hline $\mathrm{TNF}-\alpha(\mathrm{pg} / \mathrm{ml})$ & $5.0 \pm 5.9$ & $9.4 \pm 1.0$ & $19.1 \pm 1.3$ & $<0.0001$ \\
\hline
\end{tabular}

MNA: Mini nutritional assessment; BMI: body mass index; TNF- $\alpha$ : tumor necrosis factor-alpha.

CRC patients were significantly lower than in healthy subjects $(2.8 \pm 1.5 \mathrm{~g} / \mathrm{dl}$ vs. $4.3 \pm 0.42 \mathrm{~g} / \mathrm{dl} ; p<0.001, t$-test $)$ and $36.9 \pm 10.7 \%$ vs. $47.5 \pm 1.4 \% ; p<0.001, t$-test $)$.

According to the MNA score, CRC patients were divided into three groups: 23/78 (29.4\%) well nourished, 36/78 $(46.1 \%)$ at risk of malnutrition and 19/78 (24.5\%) malnourished; the latter had suffered a weight loss greater than $10 \mathrm{~kg}$ in the previous six months associated with reduction of food intake due to nausea, dysgeusia and early satiety. The means \pm SD of nutritional and inflammatory parameters in the three subgroups of CRC patients are listed in Table II.

The gender of malnourished patients was $58 \%$ male and $42 \%$ female while in the group at risk of malnutrition, $58 \%$ was female and $42 \%$ male. The analysis of variance (ANOVA) performed to analyze the means of anthropometric and laboratory parameters between the three sub-groups of patients showed a significant increase of IL-6, TNF- $\alpha$, and CRP serum levels in malnourished and at risk of malnutrition patients $(p<0.0001, p<0.0001$ and $p<0.0001$ respectively); (Table II). Concerning, albumin, TRF and HCT, lower means were observed in malnourished and at risk of malnutrition patients compared to the well-nourished group $(p<0.0001$, $p<0.0001, p=0.004$ respectively).

The comparison of BMI in the three subgroups showed that gender ratio was similar among the BMI group (data not shown in table), while the mean ages were higher in higher BMI levels. The percentage of malnourished and at risk of malnutrition patients was significantly higher in the lower BMI groups. IL-6 serum levels decrease as BMI increases, while higher TRF, HCT and albumin serum levels were found in the subgroup of well-nourished patients who also had a higher BMI.

According to Pearson's correlation, the MNA score was positively correlated to albumin (malnourished patients $v s$.
Table III. Results related to "screening" section of MNA of CRC patients.

\begin{tabular}{lcc}
\hline & $\begin{array}{c}\text { At risk malnutrition } \\
\text { patients } \%\end{array}$ & $\begin{array}{c}\text { Malnourished } \\
\text { patients } \%\end{array}$ \\
\hline Body Mass Index & $21<\mathrm{BMI}<25$ & $19<\mathrm{BMI}<25$ \\
Weight loss $>10 \%$ in past 6 months & $30 \%$ & $35 \%$ \\
Psychological stress & $15 \%$ & $28 \%$ \\
$\begin{array}{l}\text { Muscle Mass Loss } \\
\text { Reduction of Intake Food } \\
\text { (appetite loss or altered }\end{array}$ & $20 \%$ & $35 \%$ \\
taste perception) & $45 \%$ & $70 \%$ \\
\hline
\end{tabular}

lower albumin serum levels $r=0.459)$, IL-6 levels (malnourished patients vs. higher IL-6 levels $\mathrm{r}=0.638$ ) and lower BMI (in malnourished patients $\mathrm{r}=0.492$ ).

Table III show the results of the screening section of the mini nutritional assessment that emphasize that most muscle loss (more than $10 \%$ less than the normal range) it is found among the malnourished patients compared to those at risk of malnutrition and most malnourished subjects had psychological distress (grief, anxiety, worry) a year prior to the diagnosis of cancer.

The Box and Wisker plots in Figures 1 and 2, show the comparison of the mean concentration of Albumin and IL-6 serum levels between the three subgroups of CRC patients.

\section{Discussion}

According to the WHO, malnutrition can be defined as the cellular imbalance between intake of nutrients and energy which results in altered metabolism, impaired function and 


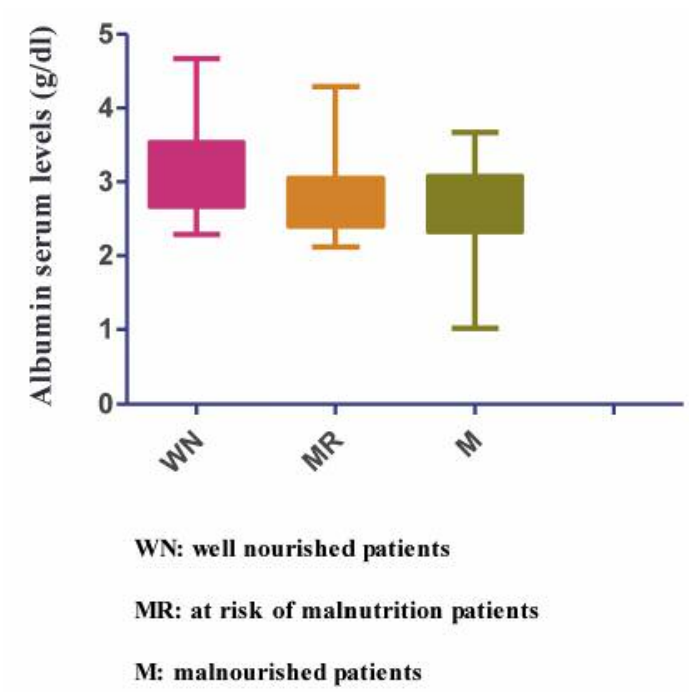

Figure 1. Comparison of the mean concentration albumin serum levels in the three subgroups of CRC patients.

loss of body mass. Nutrients can be divided into micronutrients such as vitamins, minerals, and trace elements, and macronutrients such as carbohydrates, proteins and fats (35). Marasmus and Kwashiokor represent the two major classifications of macronutrient malnutrition. Marasmus is the type of malnutrition observed in patients with prolonged fasting or inadequate food intake in which, although the diet may contain an acceptable protein to energy ratio, the utilization of endogenous fat and muscle tissue reserves for energy is present, Kwashiokor results from a deficit of protein despite a relative adequacy of energy, and may develop over a shorter period of time $(36,37)$.

PEM is a syndrome frequently associated with cancer patients and may have a significant impact on prognosis; in fact, it is associated with a decrease of physical strength, reduced tolerance to cancer treatment, reduced survival, and longer hospitalization time.

As widely reported in literature, the systemic effects of PEM in the oncology patient are due to the synergism of the action of circulating factors in part produced by cancer cells, such as proteolysis inducing factor (PIF) and lipid mobilizing factor (LMF) (38), and partly produced by macrophages (39, 40 ); a key role is played by inflammatory cytokines (IL-6 and TNF-a) produced by the tumor and activated by the immune system. The catabolic effects of these cytokines leads to deleterious effects in the patient, altering energy metabolism, body composition, nutritional status and immune function by activating the inflammatory acute phase response with reduced synthesis of proteins (albumin and transferrin) and an increase of the C-reactive protein (41). Several authors have shown a good correlation between

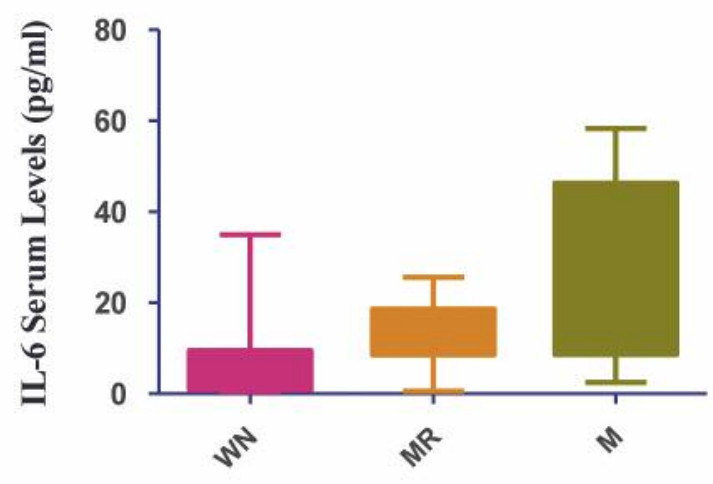

WN: well nourished patients

MR: at risk of malnutrition patients

M: malnourished patients

Figure 2. "Comparison of the mean concentration IL-6 serum levels in the three subgroups of CRC patients"

malnutrition and inflammation in cancer patients (42-44), particularly those suffering from gastro-intestinal tumors. The problem in patients undergoing colon resection is that very often the condition of malnutrition is overlooked because the patients can maintain normal weight and anthropometric measurements. Only a careful physical evaluation and review of the haematological parameters can diagnose this syndrome, which is often associated with a large serum albumin loss, decrease in hematocrit and transferrin levels, increased C-reactive protein (45), and not least the rise of pro-inflammatory cytokines that play a key role in the diagnosis of malnutrition.

In CRC patients undergoing surgery secondary causes can occur such as an altered integrity of the gastrointestinal tract, or post-surgical syndromes such as intestinal bad absorption, nausea, vomiting, appetite loss, and dysgeusia that can cause significant weight loss (>10\% in 6 months) (46); It is therefore important to carry out a timely assessment of nutritional status in order to avoid a decline in health of the patient and the onset of cancer cachexia which causes $20 \%$ of the deaths, as well as worsening prognosis due to rendering chemo or radio treatments ineffective and leading to interruption of therapy.

The objective of this study was to evaluate early, in a case series of 78 patients undergoing abdominal surgery those at risk of malnutrition or malnourished. In agreement with the mini nutritional assessment our results show that more than $50 \%$ of CRC patients do not have a normal nutritional profile and about a quarter of cases are already classified as malnourished. The most significant data of this study demonstrate that there is correlation between nutritional 
status and inflammation when comparing all CRC patients with the healthy control group, both for nutritional and inflammatory parameters in the 3 subgroups of CRC patients (WN, UM, and M patients).

According to results reported by Read et al. (47), weight loss, fatigue and malnutrition are both related to higher energy expenditure and higher inflammation status in CCR, so patients at risk of malnutrition and malnourished have lower albumin (48), transferrin, and value hematocrit serum levels compared to those with normal nutritional status. In contrast the results show an important inflammatory state with higher serum levels of IL-6, TNF-alpha (49), and CRP in cancer patients compared to healthy controls, and an average concentration significantly higher in the malnourished subgroup and in those at risk of malnutrition, suggesting the importance of adequate nutritional intervention in these patients before the start of cancer treatment (chemotherapy or radiotherapy) in order to maintain and improve response to treatment, nutritional status and quality of life, as well as to greatly reduce the time and cost of hospitalization.

\section{Acknowledgements}

This work has been funded by the Ministry of Health as part of the 2013-2016 Current Research project entitled: "Polymorphism ADIPOQ SNP rs 266,729 (C-11374G) of adiponectin gene, and levels of pro-inflammatory cytokines involved in the process of carcinogenesis in patients with colorectal cancer: nutritional intervention and proteomic profile in obesity control". The Authors would like to thank Caroline Oakley for manuscript revision.

\section{Conflicts of Interest}

The Authors have no conflict of interest in the publication of manuscript.

\section{References}

1 Parkin DM, Bray F, Ferlay J and Pisani P: Global cancer statistics 2002. Cancer J Clin 55(2): 74-108, 2002.

2 De Cosse JJ, Ngoi SS, Jacobson JS and Cennerazzo WJ: Gender and colorectal cancer. Eur J Cancer Prev 2(2): 105-115, 1993.

3 AIRTUM Working Group: Prevalence and cure of cancer in Italy. Epidemiol Prev 38(6 Suppl 1): 1-144, 2014.

4 Troisi RJ, Freedman AN and Devesa SS: Incidence of colorectal carcinoma in the US. An update of trends by gender, race, age, subsite, and stage, 1975-1994. Cancer 85: 1670-1676, 1999.

5 Townsend CM Jr, Beauchamp RD, Evers BM, Mattox KL and Sabiston C: Textbook of surgery: the biological basis of modern surgical practice. 16th ed. eds. Philadelphia PA: WB Saunders, 2001.

6 Kwak EL and Chung DC: Hereditary colorectal cancer syndromes: an overview. Clin Colorectal Cancer 6: 340-344, 2007.

7 Stoffel E and Lynch M: Syndrome/Hereditary non-polyposis Colorectal Cancer (HNPCC). Minerva Gastroenterol Dietol 56(1): 45-53, 2010.
8 Al-Sukhni W, Aronson M and Gallinger S: Hereditary colorectal cancer syndromes: familial adenomatous polyposis and lynch syndrome. Surg Clin North Am 88(4): 819-844, 2008.

9 Renehan AG, Tyson M, Egger M, Heller RF and Zwahlen M: Body-mass index and incidence of cancer: a systematic review and meta-analysis of prospective observational studies. Lancet 371(9612): 569-578, 2008.

10 Harriss DJ, Atkinson G, Batterham A, George K, Cable NT, Reilly T, Haboubi N, Renehan AG and Colorectal Cancer, Lifestyle, Exercise And Research Group: Lifestyle factors and colorectal cancer risk (2): a systematic review and meta-analysis of associations with leisure-time physical activity. Colorectal Dis 11(7): 689-701, 2009.

11 Miller P E, Lazarus P, Lesko SM, Muscat JE, Harper G, Cross AJ, Sinha R, Ryczak K, Escobar G, Mauger DT and Hartman TJ: Diet Index-Based and Empirically Derived Dietary Patterns Are Associated with Colorectal Cancer Risk. J Nutr 140(7): 1267-1273, 2010.

12 Liang PS, Chen TY and Giovannucci E: Cigarette smoking and colorectal cancer incidence and mortality: systematic review and meta-analysis. Int J Cancer 124(10): 2406-2415, 2009.

13 Cho E, Smith-Warner SA, Ritz J, van den Brandt PA, Colditz GA, Folsom AR, Freudenheim JL, Giovannucci E, Goldbohm RA, Graham S, Holmberg L, Kim DH, Malila N, Miller AB, Pietinen P, Rohan TE, Sellers TA, Speizer FE, Willett WC, Wolk A and Hunter DJ: Alcohol intake and colorectal cancer: a pooled analysis of 8 cohort studies. Ann Intern Med 140: 603-613, 2004.

14 Freeman H J. Colorectal cancer risk in Crohn's disease: World J Gastroenterol 14(12): 1810-1811, 2008.

15 Mayer RJ: Lower Gastrointestinal Cancers. In: Kasper D, Fauci A, Hauser S, Longo D, Jameson J, Loscalzo J editors: Harrison's Principles of Internal Medicine, 19e. New York, NY: McGrawHill, 2015.

16 Bedikian AY, Chen TT, Malahy MA, Patt YZ and Bodey GP: Prognostic factors influencing survival of patients with advanced colorectal cancer: hepatic-artery infusion versus systemic intravenous chemotherapy for liver metastases. J Clin Oncol 2(3): 174-180, 1984.

17 Persson C and Glimelius B: The relevance of weight loss for survival and quality of life in patients with advanced gastrointestinal cancer treated with palliative chemotherapy. Anticancer Res 22(6B): 3661-3668, 2002.

18 Kishimoto T: IL-6: from its discovery to clinical applications. Int Immunol 22(5): 347-352, 2010.

19 Wolsk E, Mygind H, Grøndahl TS, Pedersen BK and van Hall G: IL-6 selectively stimulates fat metabolism in human skeletal muscle. Am J Physiol Endocrinol Metab 299(5): E832-840, 2010.

20 Anand NSCC and Alam MN: The malnutrition inflammation complex syndrome-the micsing factor in the perio-chronic kidney disease interlink. J Clin Diagn Res 7(4): 763-767, 2013.

21 Aviles A, Yañez J, López T, García EL, Guzmán R and DíazMaqueo JC: Malnutrition as an adverse prognostic factor in patients with diffuse large cell lymphoma. Arch Med Res Spring 26(1): 31-34, 1995.

22 Lai SL and Perng RP: Impact of nutritional status on the survival of lung cancer patients. Zhonghua Yi Xue Za Zhi (Taipei) 61(3): 134-140, 1998.

23 Gupta D, Lammersfeld CA, Burrows JL, Dahlk S L, Vashi P G, Grutsch J F, Hoffman S and Lis CG: Bioelectrical impedance phase 
angle in clinical practice: implications for prognosis in advanced colorectal cancer. Am J Clin Nutr 80(6): 1634-1638, 2006.

24 Kutsal DA, Kürşat S, İnci A, Ulman C and Ozan Ütük I: The relationship between malnutrition subgroups and volume parameters in pre-dialysis patients. Saudi J Kidney Dis Transpl 27(1): 81-87, 2016

25 Alberda C, Graf A and McCargar L: Malnutrition: etiology, consequences, and assessment of a patient at risk. Best Pract Res Clin Gastroenterol 20(3): 419-439, 2006.

26 Hermanek P and Sobin LH (Eds): International Union Against Cancer (UICC):TNM classification of malignant tumors. 4th Ed, Springer Verlag, Berlin, 1987.

27 Committee on Diet and Health, Food and Nutritional Board, Commission of Life Sciences, National Research Counsil Diet and Health: Implications for reducing chronic disease risk. Washington DC: National Academy Press, 1989.

28 Guigoz Y: The Mini Nutritional Assessment (MNA) review of the literature-What does it tell us? J Nutr Health Aging 10(6): 466-485; Discussion 485-487, 2006.

29 Read JA, Crockett N, Volker DH, MacLennan P, Choy ST, Beale $\mathrm{P}$ and Clarke SJ: Nutritional assessment in cancer: comparing the Mini-Nutritional Assessment (MNA) with the scored PatientGenerated Subjective Global Assessment (PGSGA). Nutr Cancer 53(1): 51-56, 2005.

30 Slaviero KA, Read JA, Clarke SJ and Rivory LP: Baseline nutritional assessment in advanced cancer patients receiving palliative chemotherapy. Nutr Cancer 46(2): 148-157, 2003.

31 Ferguson ML, Bauer J, Gallagher B, Capra S, Christie DR and Mason BR: Validation of a malnutrition screening tool for patients receiving radiotherapy. Australas Radiol 43(3): 325-327, 1999.

32 Tsai AC, Hsu WC, Chan SC and Chang TL: Usefulness of the mini nutritional assessment in predicting the nutritional status of patients with liver cancer in Taiwan. Nutr Cancer 63(3): 334341, 2011.

33 Segura A, Pardo J, Jara C, Zugazabeitia L, Carulla J, de Las Peñas R, García-Cabrera E, Luz Azuara M, Casadó J and Gómez-Candela C: An epidemiological evaluation of the prevalence of malnutrition in Spanish patients with locally advanced or metastatic cancer. Clin Nutr 24(5): 801-814, 2005.

34 Slaviero KA, Read JA, Clarke SJ and Rivory LP: Baseline nutritional assessment in advanced cancer patients receiving palliative chemotherapy. Nutr Cancer 46(2): 148-157, 2003.

35 World Health Organization. Malnutrition-The Global Picture, 2000 .

36 Stratton RJ, Green CJ and Elia M: Scientific Criteria for defining malnutrition. In Disease related malnutrition: an Evidence-based approach and treatment. 1st edn Cambridge: CAB International 1-34, 2003.

37 Barton RG: Nutrition and support in clinical illness. Nutr Clin Pract 9: 127-139, 1994.

38 Deans DA, Wigmore SJ, Gilmour H, Tisdale MJ, Fearon KC and Ross JA: Expression of the proteolysis-inducing factor core peptide mRNA is upregulated in both tumour and adjacent normal tissue in gastro-oesophageal malignancy. Br J Cancer Mar 94(5): 731-736, 2006

39 Bing C, Bao Y, Jenkins J, Sanders P, Manieri M, Cinti S, Tisdale MJ and Trayhurn P: Zinc-alpha2-glycoprotein, a lipid mobilizing factor, is expressed in adipocytes and is up-regulated in mice with cancer cachexia. Proc Natl Acad Sci USA 101(8): 25002505, 2004.
40 Islam-Ali B, Khan S, Price SA and Tisdale MJ: Modulation of adipocyte G-protein expression in cancer cachexia by a lipidmobilizing factor (LMF). Br J Cancer 85(5): 758-763, 2001.

41 Tisdale MJ: Molecular pathways leading to cancer cachexia. Review. Physiology (Bethesda) 20: 340-348, 2005.

42 Tan CS, Read JA, Phan VH, Beale PJ, Peat JK and Clarke SJ: The relationship between nutritional status, inflammatory markers and survival in patients with advanced cancer: a prospective cohort study. Support Care Cancer 23(2): 385-389, 2015.

43 Sánchez-Lara K, Turcott JG, Juárez E, Guevara P, NúñezValencia C, Oñate-Ocaña L F, Flores D and Arrieta O: Association of nutrition parameters including bioelectrical impedance and systemic inflammatory response with quality of life and prognosis in patients with advanced non-small-cell lung cancer: a prospective study. Nutr Cancer 64(4): 526-534, 2012.

44 Baldwin C: Nutritional support for malnourished patients with cancer. Curr Opin Support Palliat Care 5(1): 29-36, 2011.

45 Chung YC and Chang YF: Serum C-reactive protein correlates with survival in colorectal cancer patients but is not an independent prognostic indicator. Eur J Gastroenterol Hepatol 15(4): 369-373, 2003.

46 Dewys WD, Begg C, Lavin PT, Band PR, Bennett JM, Bertino JR, Cohen MH, Douglass HO Jr., Engstrom PF, Ezdinli EZ, Horton J, Johnson GJ, Moertel CG, Oken M M, Perlia C, Rosenbaum C, Silverstein MN, Skeel RT, Sponzo RW and Tormey DC: Prognostic effect of weight loss prior to chemotherapy in cancer patients. Eastern Cooperative Oncology Group Am J Med 69(4): 491-497, 1980.

47 Read JA, Choy ST, Beale PJ and Clarke SJ: Evaluation of nutritional and inflammatory status of advanced colorectal cancer patients and its correlation with survival. Nutr Cancer 55(1): 78-85, 2006.

48 Nazha B, Moussaly E, Zaarour M, Weerasinghe C and Azab B: Hypoalbuminemia in colorectal cancer prognosis: Nutritional marker or inflammatory surrogate? World J Gastrointest Surg 7(12): 370-377, 2015.

49 Walsh D, Mahmoud F and Barna B: Assessment of nutritional status and prognosis in advanced cancer: interleukin-6, Creactive protein, and the prognostic and inflammatory nutritional index. Support Care Cancer 11(1): 60-62, 2003.

50 Deans DA, Wigmore SJ, Gilmour H, Tisdale MJ, Fearon KC and Ross JA: Expression of the proteolysis-inducing factor core peptide mRNA is up-regulated in both tumour and adjacent normal tissue in gastro-oesophageal malignancy. $\mathrm{Br} \mathrm{J}$ Cancer 94(5): 731-736, 2006.

51 Mantovani G, Macciò A, Lai P, Massa E, Ghiani M and Santona MC: Cytokine activity in cancer-related anorexia/cachexia: role of megestrol acetate and medroxyprogesterone acetate. Semin Oncol 25(2 Suppl 6): 45-52, 1998. 